\title{
The necessity of a media literacy module within journalism or media studies curricula
}

\author{
Fidelia van der Linde
}

\begin{abstract}
Media today is more omnipresent covering all aspects of society, ranging from historical to topical to social and political, thereby forming an integral part of people's lives. In the South African context, the introduction of democracy, coupled with numerous global technological developments, has dramatically altered the media landscape rendering it more liberal with an increased exponential content. In most democratic countries media literacy education is considered the preferred alternative to censoring and boycotting. This is to empower both media professionals and consumers thereby allowing them to analyse critically, monitor and moderate media messages in order to reduce any negative impacts of the media and ensure enhanced enjoyment and discourse. The need has been motivated for a media literacy module to be included in the journalism or media studies curricula at undergraduate level. This article highlights the importance of media literacy education - especially in terms of fostering a democracy - and outlines the typical media literacy curricula suitable for journalism students.
\end{abstract}

\section{Keywords}

analytical, censorship, contextual knowledge, critical thinking, democracy, engagement, media awareness, media literacy, perspective, stereotypes

\section{Table of contents}

1.1 Introduction

1.2 The definition of media literacy

1.3 The importance of media literacy education

1.4 Theoretical discussion on media literacy

1.5 Outline of the typical media literacy module in the journalism curriculum

1.5.1 Introduction

1.5.2 Course outline

1.5.3 Outputs and outcomes

1.5.3.1 Outputs

1.5.3.2 Outcomes

1.6 Challenges pertaining to the media literacy module

1.7 Conclusion

1.8 References 
2010 Vol 4 (2)

\subsection{Introduction}

As evidenced from the billboards along the roadside, branding on bus stops, numerous television programmes and the magazines in the doctor's waiting room, the media are everywhere. 'Media no longer just shape our culture - they are our culture' (Thoman \& Jolls, 2004:18). The media therefore affect and influence one's understanding of numerous factors such as society, politics and the world in general (Salzburg Academy on Media and Global Change website, 2010:n.p):

There is no global issue, no political arena, no academic discipline in which the statement of problems and the framing of possible solutions are not influenced by media coverage.

Yet, most people are not acutely aware of how much media they are exposed to 'because much of our exposure to media message is not planned by us' (Potter, 2008:166).

Therefore, media literacy skills are essential in terms of educating people to become more critically aware of the media they consume so that they can protect themselves from unsuitable messages, have a better understanding of the media and experience enhanced enjoyment (Potter, 2008:11).

During colonial times in South Africa, press freedom was a contentious issue and the media were embroiled in a bitter battle with authoritarian colonial governors (Eribo \& Jong-Ebot, 1997:80). Thereafter, after more than three decades of 'government censorship and restrictions on press ownership' (Eribo \& Jong-Ebot, 1997:85), the South African media could operate in a climate of freedom as from 1990, which was roughly the same time as when liberation movements were unbanned in the country (Eribo \& Jong-Ebot, 1997:77). Media literacy is considered an alternative to pre-publishing censorship or boycotting the media (Share, Jolls \& Thoman, 2005:85).

The advent of democracy - which also signified the end of media censorship - in South Africa in 1994, coupled with globalisation and rapidly developing technologies, has brought about significant changes in the South Africa media landscape (Fourie, 2001:569, 570). Although freedom of expression is essential in a democracy, it can mean that vulnerable sectors of society such as children could be exposed to material that is potentially harmful or could have negative effects, and therefore media literacy is crucial (Fourie, 2001:571).

\subsection{The definition of media literacy}

The concept of media literacy dates back to the 1970s amid concerns about the effects of violent television programmes on children (Brown, 1991, as cited in Yates, 2004:6).

Media literacy has parallels with traditional literacy (the ability to read and write text) as it is in essence the ability to 'read' and 'write' information or media messages. It is a set of perspectives that can be used to decipher, understand and interpret the meaning of media messages (Potter, 2008:19). Media literacy can be defined as 'the ability to access, analyse, evaluate and communicate messages in a wide variety of forms' (The Aspen Institute website, 1993:n.p, as cited in Hobbs, 1998:n.p.). The British broadcasting regulator, Ofcom, provided a more detailed definition for the term (The BBC Trust, 2010:n.p):

At its simplest level media literacy is the ability to use a range of media and be able to understand the information received. At a more advanced level it moves from 
recognising and comprehending information to the higher order critical thinking skills such as questioning, analysing and evaluating that information. This aspect of media literacy is sometimes referred to as 'critical viewing' or 'critical analysis'.

Another media literacy expert summarised the term as follows (Messaris, 1998:1)

In a nutshell, media literacy can be defined as knowledge about how the mass media function in society. Ideally, this knowledge should encompass all aspects of the workings of the media: in their economic foundations, organizational structures, psychological effects, social consequences, and above all, their 'language,' that is, the representational conventions and rhetorical strategies of ads, TV programs, movies, and other forms of mass media content.

Media literacy is a multi-dimensional concept and involves a myriad of skills and knowledge, ranging from analysing and evaluating a media message, and engaging with the media, to creating one's own media (Thoman \& Jolls, 2004:19), plus an understanding the mechanics of the media industry. Media literacy is a life-long education process, with informed 'inquiry' and the ability to critically engage with the media as its core essence (Share, Thoman \& Jolls, 2005:85).

According to the Salzburg Academy on Media and Global Change (Salzburg Academy on Media and Global Change website, 2010:n.p), the media literacy framework can be divided into five topics, and these topics relate to any media, anywhere in the world:

- Access to media

- Awareness of media's power

- Assessment of how media cover international events and issues

- Appreciation for media's role in creating civil societies, and

- Action to encourage better communication across cultural, social and political divides.

Potter (2008:30) referred to numerous scholars who used the term 'critical media literacy' to describe the skill of evaluating messages.

\subsection{The importance of media literacy education}

Media literacy is important because it develops critical thinking skills, produces informed citizens who develop democracy, encourages a deeper understanding of communication technologies and fosters proactive media consumers (Media Awareness Network website, 2010:n.p). Media literacy education provides a guideline for 'living, working and citizenship in the 21 st century' (Thoman \& Jolls, 2004:18) and creates a framework so that people can 'access, analyse, evaluate, communicate and create messages (National Association for Media Literacy Education website, 2008:n.p). These analytical skills are the cornerstone of informed inquiry and are essential for 'full citizenship in a democratic society and a global economy' (Thoman \& Jolls, 2004:23). Although these media literacy skills are vital on a global scale, it is especially necessary in developing countries where an active citizenry can further promote a democracy and monitor issues such as corruption or propaganda (Roberts, 2009:153).

Media education is an essential if citizens are to make rational decisions, become effective change agents and have an active involvement in their system of governance (Gitlin, 1990:n.p). 


\section{Vol 4 (2)}

In a report entitled Empowering Youth Worldwide, media literacy expert Paul Mihailidis (2009:9) warned that lack of media literacy education in developing countries can lead to civic disengagement:

Unless students are specifically taught about the basic rights of free speech and free press in the context of their media literacy courses, they may become more cynical and disengaged about their social institutions, including the government and media.

Media literacy empowers people to develop their knowledge base, and form opinions and perceptions on virtually any issue, based on what is reported by the media (Potter, 2008:12), and creates a better understanding of the dynamics between 'information, community, and democracy' (Mihailidis, 2009:4). It helps develop knowledge about aspects such as media effects, media content and media industries so that people are able to derive meaning from media messages and use it to promote their own goals, instead of simply being conditioned by the media into habitual exposure (Beckett, 2008:14). Potter (2008:39) supported this statement:

... increasing your media literacy means doing particular things when you are paying attention to messages so that you control the coding of your mental processes, so that when those mental processes run automatically they are serving your needs rather than the needs of the mass media or of advertisers.

Because media literate people are tuned into hidden agendas, sensitive to constructed messages and stereotypes, they are able to question why certain groups are not represented in the media, obtain information from a host of other sources and yet still enjoy the media for entertainment purposes (Media Awareness Network website, 2010:n.p). Citing the Partnership for $21^{\text {st }}$ Century Skills (2003), Thoman and Jolls (2004:21) quoted that media literacy skills, based predominantly on informed, critical inquiry, is essential in a 'multi-tasking, multi-faceted, technology-driven, diverse, vibrant world'.

Considering that - as a result of technology and subsequently, social networking sites and blogs everyone is able to produce media content, it is imperative that all sectors of society are educated to become critical and analytical regarding media messages. Media literacy therefore serves as a 'coherent and consistent process for analysing content and managing information, skills beneficial to individuals as they are applicable to many other personal and professional issues (Thoman \& Jolls, 2004:22), and society as a whole because citizens are subsequently able to contribute to the public discourse (Share, Jolls \& Thoman, 2005:4).

Media literacy is not needed in the future, it is needed now, urgently, to assure that our citizens are equipped to make the decisions and contributions a global economy and global culture demand of them (Thoman \& Jolls, 2004:21).

Other researchers concurred about the need to implement media literacy education as soon as possible: 
The reality is that media literacy is more urgent today than ever before. The Millennial generation has tools at its disposal that empower its members to become citizen journalists and create and experience media in ways previous generations couldn't imagine, let alone develop curricula for (Hannah, 2009:n.p).

Gitlin (1990:n.p) also highlights the dire need for media literacy education based on media saturation in society; the need for citizens to become less dependent and not so easily influenced by the media, the concentration of media ownership, the importance of media in a democracy, and the infinite increase of visual communication and information, partially due to the very high penetration of cellphones, which are frequently used to access the Internet. Despite the wealth of information available, there has not been 'a comparable increase in our human capacity to understand, manage, share, and productive use this voluminous wealth of information' (Kubey, 2001:xviii).

Generally, these critical analysis skills are not specifically taught as a specialised module, but emerge as the by-product of another subject, such as media history, ethics or advertising (for example, the persuasive techniques used to market products). Because media literacy education is concerned with the process of understanding media instead of specific content (Thoman \& Jolls, 2004:23), it does warrant becoming a stand-alone academic subject in the journalism or media studies curriculum at an under-graduate level. A media literacy module, which is included in the standard journalism curriculum, can be justified because 'journalists need to have a thorough understanding of our mediated/mediating world' (Rabe (2009:n.p) as cited in Mihailidis, 2009:11).

In America, a bill entitled the $21^{\text {st }}$ Century Skills Incentive Fund Act was introduced which stated the importance of teaching 'critical thinking and problem solving skills, communication skills, creativity and innovation skills, collaboration skills, contextual learning skills, and information and media literacy skills' (Hannah, 2009:n.p). As a result of globalisation, information and technology are no longer limited to specific geographical areas, and therefore, this statement is also applicable in the South African journalism or media studies curriculum context. Students worldwide face the same challenges and as a result, need to understand the importance of information in an 'increasingly hyper media age' (Mihailidis, 2009:4). Executive director of The Freedom Forum Media Studies Centre at Columbia University in New York, Everette Dennis, provided the following analogy to stress the importance of media literacy:

Media illiteracy is potentially as damaging and poisonous to the human spirit as contaminated water and food is to our physical well-being (Dennis, 1993, as cited in Potter, 2004:261)

People who have low levels of media literacy therefore have a false sense of awareness and have limited or weak perspectives on the media. Such people have smaller, more superficial, and less organised knowledge structures, which provide an inadequate perspective to use in interpreting the meaning of a media message (Potter, 2004:110).

\subsection{Theoretical discussion on media literacy}

As a result of the countless media messages available, and the prolific creation of new media messages, people are not critically analysing these but are in auto-pilot mode when exposed to 
them (Potter, 2004:3), and therefore the need exists for a theory of media literacy. Potter (2004:39) expressed the need for a theory of media literacy that

...explain [s] the media potentials (for good as well as for harm), the process of how those potentials grow into actualities, and how people can control that process for themselves.

Because media literacy levels are based on personal experiences and goals, the theory of media literacy cannot be any of the following (Potter, 2004:124):

- it cannot prescribe specific procedures because everyone approaches media messages from their unique perspective

- it cannot be specific, detailed or prescriptive but can provide the framework for generic procedures that can be used to approach information processing.

However, scholar Everett Rogers' theory of innovation diffusion can be applied with the aim of increasing the adoption of media literacy modules in journalism or media studies curriculums (Yates, 2004:1) in South Africa. The theoretical framework which underpins this article approaches the topic first by means of a general theory of innovation diffusion, and then, more specifically, media literacy as a technological innovation.

Regardless of the nature of the innovation, the nature and manner in which people adopt that particular innovation follows the same format and trend, and this is referred to as the diffusion of innovation theory (Fourie, 2001:299). This theory is twofold with regards to the media - either the media itself can be considered an innovation, or the media assists with creating awareness of an innovation (Fourie, 2001:299). The adoption of an innovation is dependent on these factors (Yates, 2004:1):

- the nature of the innovation

- the awareness created about the innovation by means of various communication channels

- timing of the innovation, and

- the society to which the innovation is introduced.

The diffusion of innovation theory can be summarised according to the following stages, although not all innovations necessarily go through these stages or are adopted at all (Fourie, 2001:300):

- awareness: usually by means of the mass media, the public become aware of a new innovation.

- interest: people develop an interest and are eager to learn more about the particular innovation.

- assessment: people evaluate the innovation based on all the information obtained.

- trial: interested parties apply the innovation on a small scale.

- adoption: an increasing number of people start adopting or using the innovation on a full scale. The adoption of the innovation increases (following a S-curve on a graph) and eventually evens out.

Media literacy is a technological innovation as the concept is essentially still new to potential adopters: 
The concept of media literacy has been evolving for several years, but it is being 'marketed' as a fresh idea in its present form because educators, interest groups, and parents have recognized a need for increased media savvy among young people (Yates, 2004:4).

The diffusion of innovation theory can be used by educators to explain how and why media literacy can be worked into a journalism curriculum, and to 'predict, and account for factors than increase or impede the diffusion of innovations' (Yates, 2004:4). Due to technology, the media itself is also constantly experiencing innovation and these new media need to be introduced to society, and subsequently, a diffusion campaign must be created to increase media literacy awareness (Yates, 2004:4).

Based on the theory and aforementioned literature, it can be established that media literacy has not been adopted on a full scale by tertiary academic institutions in South Africa, but this can be achieved as people become more interested in the concept and start by applying it on a smaller scale. Although media literacy levels should already be fairly high among journalism or media studies students, the ultimate goal is to equip all South Africans to critically analyse media content to foster the development of democracy and also empower themselves.

\subsection{Outline of the typical media literacy module in the journalism curriculum}

\subsubsection{Introduction}

As the dire need for a media literacy module within the journalism or media studies curriculum has been highlighted, it is necessary to determine the course outline which is suitable for undergraduate level at a tertiary institution.

The course outline will be based on the five foundational topics synonymous with media literacy, namely access, awareness, assessment, appreciation and action (Salzburg Academy on Media and Global Change website, 2010:n.p). The course can be simplified or expanded to allow for less or more complex analysis and inquiry, depending on the existing knowledge or skills base of the intended audience. The course can be upgraded or downgraded by means of developing ageappropriate lesson plans, that includes relevant case studies, exercises and topics for discussion, which are 'applicable to students' development as informed consumers and citizens' (Hannah, 2009:n.p).

The media literacy module should equip students with the theoretical skills needed to become critical media consumers and producers, and this knowledge needs to be of such a nature that it can be applied to any media:

... the focus of media literacy is on process rather than content. ... the goal is to explore questions that arise when one engages critically with a mediated message - print or electronic. It involves posing problems that exercise higher order thinking skills - learning how to identify key concepts, make connections between multiple ideas, ask pertinent questions, identify fallacies and formulate a response (Thoman \& Jolls, 2004:23).

Media literacy educators need to avoid delving into specific details about the media such as the content or ownership, but rather focus on generic patterns and knowledge structures needed to become more media literate (Potter, 2004:vii). 
'Media literacy is a continuum, not a category' (Potter, 2008:21), meaning that even upon completion of the proposed module, the possibility still exists to improve one's knowledge and critical-thinking skills base, or improving one's understanding of the media industry as a whole.

\subsubsection{Course outline}

The theoretical concepts outlined in the media literacy module detailed below aim to foster a culture of critical media consumption, and when implemented, will be supported by practical examples and exercises, topical resources and applied learning wherever possible.

A comprehensive framework is needed to provide direction for the course as inquiry is 'a messy process because one question leads to another and yet another' (Thoman \& Jolls, 2004:24). Therefore, knowledge structures are needed with regards to media effects (for example, the effect of violence in the media on children), media content, media industries, the real world and self (Potter, 2008:12) in order to process media messages.

Media literacy education is evolving from 'protectionism' to 'empowerment', thereby underscoring the importance of critical thinking and engagement with the media (Barnes, Flanagan, Corcoran \& O’Neill, 2007:12).

The following course outline delineates key concepts of media literacy, and can be discussed as superficially, or in as much detailed needed, depending on existing media literacy skills:

- Introduction to media literacy: students need to understand the definition of the term and that it encompasses (refer to section 1.2).

- The importance of media literacy: in order to keep students motivated, it is important for them to understand that 'media literacy is education for life in a global media world' (Share, Thoman \& Jolls, 2005:85). Refer to section 1.3.

- Media literacy goals: students have to understand what they are striving towards in terms of new knowledge that needs to be acquired. Refer to section 1.5.3.

- The media industry: students need to have a broad overview of the media industry in order to understand aspects such as media ownership, globalisation and the economic factors which could potentially impact on media messages produced.

- Visual literacy: humans first learn about sight and recognition then progress to speech before learning to read and write so naturally, 'visual images play an integral part in understanding' the world (Frey \& Fisher, 2008:1). The purpose of visual literacy - an essential skill in an image-driven society thanks to globalisation and technology - is to understand and critically explore the images to decipher underlying meaning (Frey \& Fisher, 2008:1) or the ability to 'read images in a meaningful way' (Bamford, 2003:2). 'Interactive mediums rely heavily upon visual imagery, movement, drama and sound to communicate' (Bamford, 2003:7). This topic will also include fundamental elements such as symbolism, camera angle, lighting techniques (International Visual Literacy Association website, 2008:n.p) and picture composition as these all impact on the meaning of the image. This topic will also discuss the ethical considerations such as digital manipulation of images because 'manipulated images serve to re-code culture' (Bamford, 2003:7), or the publishing of sensationalist graphics in mainstream publications, and the impact of globalisation on visual literacy.

- Creating media content: media literacy education needs to incorporate the deconstruction of media messages (tearing apart an existing message to critically analyse 
and understand underlying meaning) but also the construction of new media (Thoman \& Jolls, 2004:23). Once a student is capable of analysing and evaluating media messages, they will be better equipped to engage with the media and create their own media messages.

- Popular culture: it is necessary to discuss technological transformations and subsequent popular culture, for example YouTube or MXit mobile chat, to critically engage with the media and 'decode culture' (Kubey, 2001:210). Social networking sites such as Twitter and Facebook have fundamentally changed the media landscape, and their far-reaching impact therefore cannot be omitted from this module.

- Ethics: media ethics - defined as 'a body of principles and rules, fashioned by the profession' (Bertrand, 2000:4) - can either be dealt with as a topic on its own, or can be incorporated into other topics. For example, the digital manipulation of images when teaching visual literacy poses numerous ethical questions, or the stereotyping of certain racial groups, or the debate about where to publish information that is bound to negatively affect sensitive viewers or vulnerable sectors of society.

- Core concepts and key questions: one of the leading organisations in terms of seminal work regarding media literacy education, namely the Center for Media Literacy (CML), has created a tool-kit comprising fundamental concepts and questions which is needed for analytical inquiry. The CML is an international organisation, and the core concepts and key questions are therefore also applicable in the South African context, and they can be upgraded or downgraded, based on the student's existing knowledge, to analyse a topic in far more detail. Here is a list of the CML's core concepts and key questions that form the foundation or backbone of media literacy education (Share, Jolls \& Thoman, 2005:82):

- Core Concept \#1: all media messages are 'constructed.'

- Key Question \#1: who created this message?

- Keyword: constructedness

- Core Concept \#2: media messages are constructed using a creative language with its own rules.

- Key Question \#2: what creative techniques are used to attract my attention?

- Keyword: format

- Core Concept \#3: different people experience the same media message differently.

- Key Question \#3: how might different people understand this message differently from me?

- Keyword: audience

- Core Concept \#4: media have embedded values and points of view.

- Key Question \#4: what lifestyles, values and points of view are represented in, or omitted from, this message?

- Keyword: content

- Core Concept \#5: most media messages are organised to gain profit and/or power.

- Key Question \#5: why is this message being sent?

- Keyword: purpose

- Advertising techniques: at a superficial level, advertising markets products to consumers, but advertising also sells audiences to advertisers. This topic will educate students about 
the persuasive techniques (Kubey, 2001:210) and messages used in advertising to ensure that consumers aspire to a particular lifestyle and buy products they don't actually need. This topic will also centre touch on product placement and stealth advertising, which is becoming increasingly popular as traditionally advertising methods are not as effective as a result of PVRs.

- Stereotypes: defined as a 'fixed, commonly held notion' which is based on an 'oversimplification' of some behavioural trait or appearance (The Media Awareness Network, 2010:n.p), stereotypes are embedded in media messages. Stereotypes are simplistic categorisations, relating to a variety of factors such as race, gender, religion or sexual orientation, which perpetuate social prejudice and inequalities. This topic will aim to create heightened awareness of subtle and blatant stereotypes, help to change perceptions and encourage objective reporting without the need to resort to stereotypes.

- Monitoring and evaluation of media: media content needs to be monitored to ensure that all sectors of society are represented in the media, and students need to be knowledgeable about regulatory bodies (for example, the Advertising Standards Authority of South Africa) in the media industry. The main objective of media monitoring is to maintain the watchdog role of the media and 'promote ethical and fair journalism that supports human rights' (Media Monitoring Africa website, 2010:n.p). Media monitoring involves quantitative data (numerical values) and qualitative data (textual data), and the findings of this analysis is used to determine whether there are any patterns in terms of media coverage.

Students should follow these basic steps to improve their media literacy skills:

- firstly, they must critically analyse the media content.

- they must put the media message into context.

- they must obtain information from a variety of sources and cross check the information for credibility.

- they need to become more sceptical about media messages.

- they must consciously make an effort to consume and engage with more media to get a better understanding of the industry.

'The more people know about the skills required to be media literate, the more they can control their development' (Potter, 2004:117).

\subsubsection{Outputs and outcomes}

\subsubsection{Outputs}

Upon completion of the media literacy module outlined, participants should produce a diverse variety of related outputs and should be able to:

- create quality content for numerous media such as written or audio visual media;

- improve their writing skills;

- analyse a media message and indentify the underlying message;

- monitor media messages;

- moderate media messages;

- have a better perspective on a media message; 
- engage with a regulatory authority such as the Press Ombudsman (by means of a letter or email correspondence, for example);

- engage with the media by means of an opinion article or a letter to the editor;

- identify techniques used by advertisers to sell products or services;

- identify blatant or subtle stereotypes;

- debate contentious ethical issues;

- determine the message's target audience and ask questions regarding content that was not included, and the reasons influencing content selection.

Media literate people have the ability to recognise referents, recognise patterns, put the meaning of the referent in context and develop competences (Potter, 2004:116, 118).

\subsubsection{Outcomes}

The intended outcome of the proposed media literacy module is that undergraduate journalism students must be capable of critically analysing media by means of decoding messages, understanding media effects, improving interaction with various media, engaging with regulatory authorities (Potter, 2008:15), and understanding the dynamics of the media industry in terms of ownership, control and economic influences (Messaris, 1998:70). 'The fundamental objective of media literacy is critical autonomy in relationship to all media' (Aufderheide, 1993, as cited in Yates (2004:1).

Journalism students are also expected to have a heightened sensitivity towards pertinent issues such as stereotyping, biased reporting, propaganda and psychological effects of the media, especially when vulnerable sectors of society are involved.

The vision of media literacy is to put all individuals, ultimately, in charge of their own learning, empowering them to take an active rather than a passive role in acquiring new knowledge and skills (Thoman \& Jolls, 2004:27).

Essentially, they are able to evaluate text for meaning, authenticity and credibility. Media literate people have increased awareness and should therefore be less susceptible to negative media influences, in comparison to people with lower media literacy levels, and therefore limited perspectives, who are unable to decode various layers of meaning (Potter, 2008:21,24). Livingstone (2003:10) explained:

The ability to analyse symbolic texts lies at the core of literacy, and so specification of the skills required for analysis has been the focus of media education curricula.

Apart from skills regarding mediated messages and the deconstruction thereof, journalism students should also have improved media production skills, media advocacy skills and more frequent engagement with the media. They should be empowered media consumers and confident enough to hold the media accountable and challenge them accordingly, as they should be more familiar with the key regulatory bodies, basic media law and media ethics.

Ultimately, students must acquire an 'understanding of media's contributions to civil society, public discourse, empowerment, and power sharing' (Mihailidis, 2009:12). Media literacy education strives to develop the rights of freedom of expression and encourage citizens to participate in cultural and democratic debates (Livingstone, 2003:15). 
A media literate person should be able to:

- use media effectively;

- employ critical thinking skills to evaluate media messages;

- evaluate the credibility of information;

- 'read' and understand the deeper meaning of a media message;

- appreciate numerous perspectives;

- engage critically with the media;

- understand media influence;

- have an understanding of media ownership;

- and understand the effects of the media.

\subsection{Challenges pertaining to the media literacy module}

One of the biggest hurdles to improving media literacy on a large scale in South Africa is the low level of basic literacy. Hannah (2009:n.p) states a very valid point: 'How can we expect children to read between the lines if many of them don't know how to read?'.

Poor reading and writing skills are the result of numerous 'political and economic circumstances' (Prinsloo, 1999:418). Illiteracy dates back to colonial times (with the Christian missionaries being credited as the 'major purveyors of literacy' in South Africa in the $18^{\text {th }}$ century) (Prinsloo, 1999:419) but was further entrenched among Black people during apartheid:

The changing political circumstances, associated with the shift from minority rule to an internationally recognised non-racial democracy, have led to a refiguring of conceptions of illiteracy as a social problem (Prinsloo, 1999:421).

In addition to general illiteracy, rapidly developing technology in the Information Age poses another challenge for media literacy education. An unlimited 'volume and velocity of information' and multimedia culture can make existing perceptions of 'time and space, history and geography' very outdated (Kubey, 2001:309). With new media such as an article on the Internet, it is often difficult to establish basic information such as the author or date when the content was created, let alone the credibility of that information (Livingstone, 2003:10). It is therefore crucial that students are equipped with generic critical analysis skills which can be applied to any medium or new technology:

It demands a new kind of literacy, rooted in the real world of instant information, global interactivity, and messages created on multiple media platforms (Thoman \& Jolls, 2004:19).

Another problem with the proliferation of information is that many people do not have access one of the key aspects identified of media literacy - to this media because of socio-economic reasons. The issue of the Digital Divide (a 'multidimensional phenomenon' comprising of the global divide, the social divide and the democratic divide, and referring to 'disparity within the online community' (Norris, 2001:4)), and resultant social, political and cultural isolation, is therefore intricately intertwined with media literacy. The problem of lack of access cannot be solved with a so-called quick fix because access 'rests on a dynamic and social process, not a 
one-off act of provision' (Livingstone, 2003:8) and people need first to become familiar with the media in order to critically engage with it.

Due to a combination of the infinite volume of media available, coupled with constantly developing technology and evolving popular culture, media literacy is understandably very difficult to measure and therefore difficult to include in an academic curriculum. Media literacy standards are often 'vague and inconsistent' (Thoman \& Jolls, 2004:22), making it a challenge to determine what topics should be included in the curriculum and how the success of the module will be measured by educational institutions which need quantifiable or 'universal metric and methodical testing' (Hannah, 2009:n.p).

... there was hardly a consensus on how to create a measurement protocol that can determine whether a certain media literacy curriculum is successful. ... It's not even clear what should be measured, be it analysis skills, content knowledge, motivation and engagement, attitudes, participation, or some combination of these (Hannah, 2009:n.p).

The need therefore exists for a 'consistent, measurable definition of media literacy' and a 'set of competencies to guide curriculum development' (Thoman \& Jolls, 2004:22). Some researchers believe that a form of media literacy is already included in the secondary education phase:

Ironically, schools have been teaching a form of media literacy for years. If one examines almost any English literature class, one would find critical analysis and evaluation of classic novels taking place. ... They may be taught to identify main themes, analyze metaphors, and understand points of view. Media literacy training teaches similar concepts (Yates, 2004:5).

Media literacy cannot simply be embedded in other subjects such as Media Ethics or Media History. It needs to be given priority as a stand-alone subject and form an intrinsic part of the journalism or media studies curriculum:

Until there is agreement in a country for a national need to implement media literacy, it will remain on the margins of education, reaching only a small percentage of the youth population (Mihailidis, 2009:25).

In South Africa, because the education system is focused on improving basic literacy skills, media literacy awareness is low. 'There is no analogous term for media literacy, and the concept has barely been introduced to the country at large' (Rabe (2009:n.p) as cited in Mihailidis, 2009:11).

It is important that media literacy educators have workshops to exchange ideas because the essence of the diffusion theory is based on 'modelling and imitation by potential adopters of their network partners who have adopted previously' (Yates, 2004:7).

\subsection{Conclusion}

Because we live in an information economy we are often not even aware of the vast number of media messages we are exposed to daily. It has been proposed that media literacy education be included as an independent, core module in the journalism or media studies curriculum at undergraduate level - and not simply media literacy lessons embedded in other traditional subjects - to equip and empower students to critically analyse these messages. This will result in 
an improved ability to decode a message and lead to a heightened understanding and enhanced enjoyment of the embedded meaning in media messages:

When you are media literate, you have clear maps to help you navigate better in the media world so that you can get to those experiences and information you want without becoming distracted by those things that are harmful to you. You are able to build the life that you want rather than letting the media build the life they want for you (Potter, 2008:9).

The need for improved media literacy skills can 'only be achieved in the longer-term through education' as not enough is currently being done to equip people with a 'broader understanding and skills needed in the networked world' (Beckett, 2008:161).

The completion of the proposed media literacy module will also hopefully spark a hunger to continue acquiring and developing media literacy skills - such as a more thorough understanding of media ownership or new media trends - which can be applied to any medium or mediated message. It is the responsibility of the individual to ensure that media literacy is not simply a once-off course, but rather, a lifelong learning experience and a continuous journey towards a better understanding of the media's power and influence. 'The way that people learn greater media literacy is very much a personal exploration guided and inspired by the communities involved' and ultimately, 'people learn media literacy by doing it' (Beckett, 2008:162).

A media literacy module is critical to develop informed citizens who are able and empowered to make a valuable contribution to society by fostering democracy.

\section{Author details:}

Fidelia van der Linde

MPhil student completing her degree at Stellenbosch University, in South Africa.

fidelia918@hotmail.com

\subsection{References}

Bamford, A. 2003. The visual literacy white paper. Available on the World Wide Web: http://www.adobe.com/uk/education/pdf/adobe_visual_literacy_paper.pdf. Accessed: 2009-0812.

Barnes, C., Flanagan, B., Corcoran, F. and O’Neill, B. 2007. Critical media literacy in Ireland. Available on the World Wide Web:

http://www.ubuntu.ie/documents/Radharc.Report_medialiteracy2007.pdf. Accessed: 2010-09-12.

Beckett, C. 2008. SuperMedia - saving journalism so it can save the world. West Sussex, UK: Blackwell Publishing.

Bertrand, C.J. 2000. Media ethics and accountability systems. New Jersey: Transaction Publishers.Available on the World Wide Web: http://bit.ly/9RRakQ. Accessed: 2010-09-02.

Eribo, F. and Jong-Ebot, W. (Eds). 1997. Press freedom and communication in Africa. New Jersey: Africa World Press, Inc. Available on the World Wide Web: http://bit.ly/dosRjj.

Accessed: 2010-09-18. 


\section{Vol 4 (2)}

Fourie, P.J. (Ed). 2001. Volume 1: media studies: institutions, theories and issues. Landsdowne: Juta.

Frey, N. and Fisher, D. 2008. Teaching visual literacy (using comic books, graphic novels, anime, cartoons, and more to develop comprehension and thinking skills).Available on the World Wide Web: http://bit.ly/bcuJye. Accessed: 2009-05-17.

Gitlin, T. 1990. Media literacy: education for a technological age. Center for Media Literacy. Available on the World Wide Web: http://www.medialit.org/reading-room/media-literacyeducation-technological-age. Accessed: 2010-09-05.

Hannah, M. 2009. The importance and challenges of universal media literacy education. MediaShift.Available on the World Wide Web: http://www.pbs.org/mediashift/2009/08/theimportance-and-challenges-of-universal-media-literacy-education239.html. Accessed: 2010-1002.

Hobbs, R. 1998.The seven great debates in the media literacy movement. Journal of Communication, 48(1):pp 16-32. Available on the World Wide Web:

http://www.medialit.org/reading-room/seven-great-debates-media-literacy-movement-circa- 2001 . Accessed: 2008-06-15.

International Visual Literacy Association. 2008. Online: http://www.ivla.org/. Accessed: 200903-18.

Kubey, R.W. (Ed). 2001. Media literacy in the information age: current perspectives (Volume 6). New Jersey: Transaction Publishers.

Livingstone, S. 2003. The changing nature and uses of media literacy. London: Media Culture Online.Available on the World Wide Web: http://www.european-

mediaculture.org/fileadmin/bibliothek/english/livingstone_changing_nature/livingstone_changing _nature.pdf. Accessed: 2010-09-05.

Media Awareness Network. 2010.Available on the World Wide Web: http://www.mediaawareness.ca/english/index.cfm. Accessed: 2010-10-02.

Media Monitoring Africa. 2010.Available on the World Wide Web: http://www.mediamonitoringafrica.org/. Accessed: 2010-10-02.

Messaris, P. 1998. Visual aspects of media literacy. Available on the World Wide Web: http://www.lerc.educ.ubc.ca/fac/dobson/courses/lled565d/pdfs/messaris_1998.pdf. Accessed: 2009-08-12.

Mihailidis, P. 2009. Media literacy: empowering youth worldwide. Washington, D.C.: Center for International Media Assistance.Available on the World Wide Web: http://cima.ned.org/publications/research-reports/media-literacy-empowering-youth-worldwide. Accessed: 2010-09-05. 
National Association for Media Literacy Education. 2008.Available on the World Wide Web: http://namle.net/. Accessed: 2009-06-05.

Norris, P. 2001. Digital divide: civic engagement, information poverty and the Internet worldwide. Cambridge: Cambridge University Press. Available on the Worldwide Web: http://bit.ly/c6qe8x. Accessed: 2010-10-27.

Potter, W.J. 2004. Theory of media literacy: a cognitive approach. California: Sage Publications.

Potter, W.J. 2008. Media literacy - fourth edition. USA: Sage Publications.

Prinsloo, M. 1999. Literacy in South Africa. literacy: an international handbook. Westview Press, pp. 418 - 423.Available on the World Wide Web:

http://web.uct.ac.za/depts/educate/download/99literacyinsouthafrica.pdf. Accessed: 2010-09-05.

Roberts, J. 2009. Research report: media literacy (2009). Journal of Media Literacy Education 1:2 (2010) pp.153 - 155. Washington, D.C.: Center for International Media Assistance. Available on the World Wide Web: http://jmle.org/index.php/JMLE/article/viewFile/52/28. Accessed:

2010-09-05.

Salzburg Academy on Media and Global Change. 2010.Available on the World Wide Web: http://www. salzburg.umd.edu/salzburg/new/. Accessed: 2010-09-05.

Share, J., Jolls, T. and Thoman, E. 2005. Five Key Questions that can change the world: Lesson plans for Media Literacy. Center for Media Literacy. Available on the World Wide Web: http://www.medialit.org/cml-medialit-kit. Accessed: 2009-06-05.

The BBC Trust. 2010. Media Literacy - a report into research conducted on behalf of the BBC Trust. Available on the World Wide Web :

http://www.bbc.co.uk/bbctrust/assets/files/pdf/review_report_research/ara2009_10/media_literac y.txt. Accessed: 2010-10-10.

Thoman, E. and Jolls, T. 2004. Media Literacy - A National Priority for a Changing World. American Behavioral Scientist. Vol 48:1. pp 18 - 29. Available on the World Wide Web: http://www.ac.wwu.edu/ karlberg/444/readings/priority.pdf. Accessed: 2010-09-15.

Yates, B.L. 2004. Applying diffusion theory: adoption of media literacy programs in school. Available on the World Wide Web:

http://utpjournals.metapress.com/content/318r03029261838g/fulltext.pdf. Accessed: 2009-09-12. 